\title{
Identifying the Causes Increasing the Risk of Non-Adherence in Adult Patients with Asthma: An Analysis Combining Patient Survey Data with German Claims Data
}

\author{
Sabrina Müller ${ }^{1}$ - Ulf Maywald ${ }^{2} \cdot$ Hartmut Timmermann ${ }^{3} \cdot$ Victoria Unmüßig $^{4} \cdot$ Robert Welte $^{4} \cdot$ Fränce Hardtstock $^{1}$. \\ Thomas Wilke
}

Accepted: 7 February 2021 / Published online: 24 February 2021

(c) The Author(s) 2021

\begin{abstract}
Background There exists a range of treatments in the management of asthma. Non-adherence to these medications has been identified as a factor negatively impacting the effects of treatment.

Objective The objective of this study was to identify the potential barriers to medication adherence among adult patients with asthma in Germany.

Patients and Methods A multi-center observational study was conducted addressing adult patients with asthma who were prescribed regular maintenance medication between 2014 and 2016. Data were derived from physicians' documentation as well as claims data, which were linked to the above primary observational data, and patient survey data. Adherence barriers were assessed by the validated Adherence Barriers Questionnaire, both descriptively and in a logistic regression framework. Cluster analysis identified distinct patient groups with respect to the relevance of specific adherence barriers.

Results We included 524 patients with asthma (mean age 53.1 years, $74.6 \%$ female, $43.1 \%$ allergic asthma, $37.6 \%$ nonallergic, $19.3 \%$ mixed). Most of the participants reported to face at least three barriers $(61.1 \%)$. Frequently reported barriers were the perception that medications are all harmful (53.6\% of the participants), the burden of medication co-payment (44.1\%), positive perception about current health status (39.9\%), feeling of depression (30.9\%), and the fear of side effects (27.5\%). Four distinct patient clusters could be identified: cluster 1 with a low number of barriers (28.6\% of participants), cluster 2 (11.6\%) with a comparably high number of existing barriers, cluster 3 with high importance of depression as a barrier (27.3\% of participants), and cluster 4 that was dominated by the perception that medications are all harmful (32.5\% of participants). Conclusions Results of this study provide important insights for further development of adherence programs, which should focus on distinct patients' clusters that differ substantially in the relevance of specific adherence barriers.
\end{abstract}

\section{Rationale and Background}

Asthma is one of the most common chronic respiratory diseases, affecting 235 million people of all ages worldwide [1]. In Germany, nearly $6.2 \%$ of adults are affected by asthma

Sabrina Müller

sabrina.mueller@ingress-health.com

1 Ingress-Health HWM GmbH, Alter Holzhafen 19, 23966 Wismar, Germany

2 AOK PLUS, Dresden, Germany

3 Allergopraxis Hamburg, Hamburg, Germany

4 GSK Deutschland, Munich, Germany

5 Institut für Pharmakoökonomie und Arzneimittellogistik e.V, Wismar, Germany
[2]. Asthma symptoms include wheeze, shortness of breath, chest tightness, cough, and variable expiratory airflow limitation [3]. It is a non-curable disease that negatively impacts patients' physical health, resulting in productivity losses and decreases in quality of life [4]. A number of treatment alternatives of both symptomatic (reliever medications) and long-term disease-modifying (controller medications) nature are available to patients [5]. Despite a range of treatment options, a considerable proportion of the patient population has poorly controlled asthma [6].

To maximize the therapeutic benefits, adherence to medication is essential. Non-adherence (NA), which can be defined as the extent to which a patient's medicine-taking behavior does not correspond with agreed instructions from a healthcare provider [7], as well as non-persistence (NP; early and unrecommended treatment discontinuation [8, 


\section{Key Points}

A patient questionnaire, the Adherence Barriers Questionnaire for Asthma (ABQ-Asthma), was applied to identify potential causes of medication-related nonadherence in patients with asthma.

The majority of patients with asthma experienced multiple adherence barriers where non-adherence to medication was mostly linked towards barriers related to attitude and beliefs.

Four different patient groups were identified, with patients within a group having a similar structure of adherence barriers. Patient segmentation regarding the prevalence of different adherence hurdles might be helpful when developing adherence-promoting interventions.

9]) have been associated with outcomes such as increasing asthma symptoms, anxiety, and depression, higher direct and indirect costs of care, and poorer quality of life [10,11].

Over the last decades, several interventions have been proposed to address NA/NP in asthma treatment, including among others patient education [12], simplification of treatment procedures [13], patient communication [14], and adherence feedback, a type of intervention that monitors feedback via electronic monitoring [15]. However, it was shown that there had been no overall improvement in NA rates among the general population of patients with asthma [16]. Similarly, the extent of NP to medication therapy still seems to be high $[10,15]$. This calls for a better understanding of the causes of NA/NP regarding asthma treatment.

The objective of this study was to identify the potential barriers to adherence among adult patients with asthma in Germany. Our investigation included a unique approach that linked a claims data-based assessment of adherence with a patient survey using a novel questionnaire that was adjusted to be used in patients with asthma (Adherence Barriers Questionnaire for Asthma, ABQ-Asthma).

\section{Methods}

\subsection{Study Design and Measures}

A multi-center observational study in two regions of Germany (Saxony and Thuringia; regions were determined by the coverage of the cooperating sickness fund providing the claims data) was conducted. Outpatient pulmonologists and general practitioners consecutively enrolled eligible patientswith asthma (from 01/12/2014 to 31/01/2016). Generally, patients were eligible for the study if they had been diagnosed with asthma, were at least 18 years old, and were prescribed maintenance medication at the date of study inclusion. Furthermore, each patient needed to be insured by the cooperating sickness fund and be able to participate in a phone interview in the German language. Written informed consent was obtained from each patient.

Patients were observed for a follow-up period of 12 months. The study sites recorded the main sociodemographic and clinical data at baseline via electronic data capture. Furthermore, the study sites documented recommended dosages/intake frequencies of prescribed treatments at each visit during the follow-up.

At study enrollment, patients completed the Asthma Control Test $\left(\mathrm{ACT}^{\mathrm{TM}}\right)$ via a written questionnaire. The $\mathrm{ACT} \mathrm{TM}^{\mathrm{TM}}$ is a test that specifies asthma symptom control and was used to express asthma management of the patient, thereby differentiating between uncontrolled asthma (score $<20$ ), partially controlled asthma (score 20-24), and controlled asthma (maximum score of 25) [17].

After approximately 9 months, patients completed the ABQ-Asthma through computer-assisted phone interviews conducted by trained interviewers. The ABQ is a validated instrument that has already been shown to be a practical, reliable, and valid questionnaire to assess adherence barriers in chronic indications $[18,19]$. Developed initially in indications with orally applied treatments, the ABQ was adapted to the specific needs of inhaled medications [20]. The ABQAsthma contains 16 items, with each formulated as a statement. Each item is displayed as a 4-point Likert scale with the possible answers "strongly agree", "generally agree", "generally disagree", and "strongly disagree", which were given values from 1 to 4 , or rather from 4 to 1 , depending on the formulation of each item. A higher score indicates a greater influence of a certain barrier on a patient's perception. Patients were considered to be affected by a barrier if the respective item's score was $>2$.

Adherence of patients was assessed for inhaled controller medication based on the claims data. The claims data were provided by the AOK PLUS, which is a regional healthcare provider including approximately 3.4 million members in the German states Saxony and Thuringia covering about 50\% of the regional population. The adherence of a patient was calculated using the prescription-based proportion of days covered (PDC) by any of the prescribed controller/maintenance medication. The days covered by a prescription were calculated based on the dispensing quantity of the prescription and the recommended dosage, as documented by the study site (treating physician). Furthermore, it was assumed that the days a patient stayed in a hospital were covered by inpatient medication. Stockpiling was considered by assuming that, in case there were overlapping medications, the previous supply was taken fully before the new supply was 
initiated. To calculate a prescription-based PDC between a first and a last observed prescription, a patient should have had a minimum of two prescriptions of a maintenance/ controller medication prescribed within the observational period. Therefore, an adherence assessment was not feasible for all patients who have completed the ABQ-Asthma.

\subsection{Statistical Methods}

Patients' characteristics were analyzed using descriptive statistics, including absolute and relative frequencies for categorical variables and summary statistics (mean, standard deviation) for continuous variables. Group comparisons were performed using Pearson's Chi-squared test for nominal variables and the non-parametric Mann-Whitney $U$ test for independent samples for continuous variables. The frequency of the different adherence barriers reported by the patients was analyzed, and the summary statistics for the score of each barrier were assessed.

Furthermore, a two-step cluster analysis was conducted to identify patient segments with regard to specific adherence barriers. This is an exploratory approach to reveal natural grouping, aiming to identify groups that are inherently very homogeneous and as heterogeneous as possible to other groups. Here, dichotomized variables indicating the presence of specific adherence barriers as assessed by the ABQAsthma were included as predictors. The log-likelihood was then used to compute the similarity between clusters. The final number of clusters in the model was determined by the Bayesian Information Criterion. The identified clusters were described in terms of size, the quantity of the barriers, the frequency of specific barriers, and the average PDC of patients in the specific cluster.

Finally, the probability of patients to be NA was estimated using a logistic regression model that initially included all 16 barriers assessed as independent variables. Based on a backward elimination procedure, barriers with a $p$ value $>0.050$ were excluded from the model. Generally, a patient was defined to be NA if the PDC was lower than $80 \%$. We replicated the regression estimation using a less restrict NA definition (PDC $<60 \%)$ in a sensitivity analysis. The statistical analysis was conducted using SPSS software (version 19.0; IBM, Chicago, IL, USA), Stata/MP 14, IBM SPSS Statistic software (version 20), and Microsoft Excel 2016.

\section{Results}

In total, 641 patients were initially included in the study. At 9 months of follow-up, 527 patients (82.2\%) participated in the patient survey; with three patients who were not able to complete the ABQ-Asthma. The remaining 524 patients were included in the analysis. Patients were on average 53.1 years of age, and $74.6 \%$ were female (Table 1). Most patients were diagnosed with allergic asthma (43.1\%), followed by nonallergic asthma (37.6\%) and mixed asthma (19.3\%). According to the ACT ${ }^{\mathrm{TM}}, 12.0 \%$ of patients had controlled asthma, whereas a considerable portion was either partly controlled (44.1\%) or uncontrolled (42.7\%).

According to the claims data, 185 patients did not receive or received only one prescription of a maintenance/controller medication during the study period. A claims-based adherence assessment was conducted for the remaining 339 patients. The baseline characteristics of these 339 patients, listed in Table 1, were similar to the baseline characteristics of the 524 patients who completed the ABQ-Asthma. Most of the observed patients received a combination regimen of long-acting beta2-agonists/inhaled corticosteroids during the observational period.

The majority of patients who completed the ABQ-Asthma reported to be affected by at least three barriers (61.1\%), and only $6.1 \%$ were not affected by any of the assessed barriers. As shown in Table 2, more than half of the patients (53.6\%) expressed the perception that medications, in general, are harmful and, if possible, should be avoided. Furthermore, $39.9 \%$ of the patients reported feeling healthy and therefore were sometimes unsure about the necessity to take medications daily. Another barrier reported by $44.1 \%$ of patients was the burden of co-payments. In addition, some additional factors, such as depression (30.9\%) and forgetfulness $(28.1 \%)$, were reported frequently. Regarding side effects, $27.5 \%$ of patients stated that they were afraid of the side effects of the medication, and $27.1 \%$ reported that they have stopped/would stop taking their medications or took/ would take less of them, in case they noticed/would notice side effects. Approximately one-sixth of the patients were affected by barriers to access healthcare services (e.g., a long distance to the treating physician) as well as barriers regarding the regular intake of medication (e.g., lack of belief regarding the need for a regular intake and coping behavior to stick to a regular intake). A lack of patient knowledge regarding the scope of their medication and the recommendation of healthcare professionals or a limited capability to use an inhaler were rarely reported.

A total of four different patient groups were identified within the cluster analysis. Cluster 1 consists of 150 patients (28.6\%) who have a generally low burden of adherence barriers. More than one-fifth of the patients belonging to this cluster were not affected by any barrier (Fig. 1). In all other clusters, all patients are affected by at least one barrier. Accordingly, the average number of existing barriers is lowest in Cluster 1, with a mean of 1.5 barriers per patient. Consequently, this group shows, on average, the highest PDC (mean: $84.9 \%$ ). Contrary, the 61 patients (11.6\%) assigned to Cluster 2 showed the highest barrier burden. 
Table 1 Baseline characteristics of patients included in the analysis

\begin{tabular}{|c|c|c|c|c|}
\hline \multicolumn{2}{|l|}{ Characteristics } & \multirow{2}{*}{$\begin{array}{l}\text { All included } \\
\text { patients with } \\
\text { asthma } \\
641\end{array}$} & \multirow{2}{*}{$\begin{array}{l}\text { Patients with asthma } \\
\text { completed ABQ- } \\
\text { Asthma } \\
524\end{array}$} & \multirow{2}{*}{$\begin{array}{l}\text { Patients with asthma completed } \\
\text { ABQ-Asthma and adherence } \\
\text { assessment based on claims data }\end{array}$} \\
\hline$N$ & & & & \\
\hline Age in years & Mean (SD) & $52.4(16.6)$ & $53.1(16.1)$ & $55.3(16.2)$ \\
\hline Female sex & $N(\%)$ & 472 (73.6) & 391 (74.6) & 254 (74.9) \\
\hline Body mass index & Mean (SD) & $28.6(9.2)$ & $28.7(9.8)$ & $29.0(10.4)$ \\
\hline Type of asthma ${ }^{a}$ & Allergic asthma, $N(\%)$ & $277(43.2)$ & $226(43.1)$ & $137(40.4)$ \\
\hline & Nonallergic asthma, $N(\%)$ & $236(36.8)$ & $197(37.6)$ & $139(41.0)$ \\
\hline & Mixed asthma, $N(\%)$ & $128(20.0)$ & $101(19.3)$ & $63(18.6)$ \\
\hline \multirow[t]{4}{*}{ Asthma control (ACT $\left.{ }^{\mathrm{TM}}\right)$} & Controlled $(\mathrm{ACT}=25), N(\%)$ & $75(11.7)$ & $63(12.0)$ & $38(11.2)$ \\
\hline & $\begin{array}{l}\text { Partly controlled (ACT 20-24), } \\
\quad N(\%)\end{array}$ & $279(43.5)$ & $231(44.1)$ & $142(41.9)$ \\
\hline & $\begin{array}{l}\text { Uncontrolled (ACT <20), } N \\
(\%)\end{array}$ & $267(41.7)$ & $224(42.7)$ & $149(44.0)$ \\
\hline & Unknown, $N(\%)$ & $20(3.1)$ & $6(1.1)$ & $10(2.9)$ \\
\hline \multirow{3}{*}{$\begin{array}{l}\text { Asthma exacerbation }{ }^{\mathrm{b}} \text { in the last } \\
24 \text { months }\end{array}$} & No exacerbation, $N(\%)$ & $533(86.3)$ & $455(86.8)$ & $288(85.0)$ \\
\hline & One exacerbation, $N(\%)$ & $62(9.7)$ & $52(9.9)$ & 39 (11.5) \\
\hline & $\begin{array}{l}\text { More than one exacerbation, } \\
N(\%)\end{array}$ & $26(4.1)$ & $17(3.2)$ & $12(3.5)$ \\
\hline \multirow{4}{*}{$\begin{array}{l}\text { Asthma maintenance treat- } \\
\text { ment; patients with at least } 2 \\
\text { prescriptions in observational } \\
\text { period based on claims data }^{c}\end{array}$} & $\mathrm{ICS}, N(\%)$ & $77(12.0)$ & $65(12.4)$ & $65(19.4)$ \\
\hline & ICS/LABA, $N(\%)$ & $324(50.5)$ & $270(51.5)$ & $270(79.6)$ \\
\hline & LABA, $N(\%)$ & $47(7.3)$ & $40(7.6)$ & $40(11.8)$ \\
\hline & LTRA, $N(\%)$ & $29(4.5)$ & $24(4.6)$ & $24(7.1)$ \\
\hline
\end{tabular}

$A B Q$-Asthma Adherence Barriers Questionnaire for Asthma, ACT ${ }^{\text {TM }}$ Asthma Control Test, BMI body mass index, ICS inhaled corticosteroids, $L A B A$ long-acting beta2-agonists, LTRA leukotriene receptor antagonist, $S D$ standard deviation

${ }^{\mathrm{a}}$ Assessed by the treating physician (documented at baseline via electronic case report form)

${ }^{b}$ Acute exacerbations were defined as an acute worsening of asthma symptoms requiring short-term medication, a change in long-term medication, or an asthma-related hospitalization

${ }^{\mathrm{c}}$ Column percentage can exceed $100 \%$. A patient with asthma can appear in multiple maintenance treatment groups

Nearly one-third of patients in that group reported more than five adherence barriers, and only $6.6 \%$ of the patients were affected by fewer than three barriers. On average, the patients reported 4.4 adherence barriers. Correspondingly, the average PDC was lowest in this group (mean of 75.4\%), even if the assessment could be based on only 14 patients. The number of adherence barriers that patients reported was highest for cluster 2, with an average of 4.4 barriers per patient. Clusters 3 and 4 were not superficially characterized by the number of existing barriers but by a high impact of specific barriers. All patients in Cluster 3 (143, 27.3\%) reported feeling discouraged and sometimes depressed, and mostly the frequently reported barriers were more of an unintentional nature. In contrast, Cluster 4 (170 patients, $32.4 \%$ ) is mainly driven by barriers potentially leading to intentional NA.

Based on a logistic regression estimating the probability to be classified as NA (claims-based PDC $<80 \%$ ), two specific barriers with a significant impact on the NA probability were identified: the fear of side effects and the perception that all medications are harmful. Patients reported to be affected by both barriers had an approximately $30 \%$ higher NA probability compared with patients who were not affected by these barriers. In the sensitivity analysis using a NA definition of PDC $<60 \%$, four barriers could be identified as significant explanatory NA factors. In addition to the previously identified barriers, the fact that patients felt healthy and were therefore unsure about the necessity to take their medication daily as well as the fact that patients frequently reported problems with the application of their medicine showed a significant influence. Patients reported to be affected by all four barriers showed a $73.6 \%$ higher NA probability compared with all other patients. 
Table 2 Mean item score (SD) and number of patients affected by item of the ABQ-Asthma

\begin{tabular}{|c|c|c|}
\hline & $\begin{array}{l}\text { Item score } \\
\text { Mean (SD) }\end{array}$ & $\begin{array}{l}\text { Number of patients } \\
\text { affected by the item } \\
(\text { score }>2) \\
n(\%)\end{array}$ \\
\hline "I fully understand what my doctor, nurse, or pharmacist have explained to me so far." & $1.15(0.45)$ & $11(2.10)$ \\
\hline "I can list the names of my medications and their scope without hesitation." & $1.12(0.53)$ & $22(4.20)$ \\
\hline "I trust my doctor and agree on my treatment plan with him/her." & $1.16(0.46)$ & $12(2.29)$ \\
\hline "My medications help me only if I take them on a strict regular basis as recommended." & $1.55(0.92)$ & $72(13.74)$ \\
\hline "Medications are all poison. If possible, one should avoid taking medication at all." & $2.58(1.17)$ & $281(53.63)$ \\
\hline $\begin{array}{l}\text { "I feel basically healthy. Therefore, I am sometimes unsure whether I really need to take my medication } \\
\text { daily or use my inhalers daily." }\end{array}$ & $2.22(1.15)$ & $209(39.89)$ \\
\hline $\begin{array}{l}\text { "I take my medication/my inhalers every day automatically at a fixed time or at fixed occasions (e.g., at } \\
\text { mealtimes, before bed, before brushing teeth)." }\end{array}$ & $1.6(1.05)$ & $91(17.37)$ \\
\hline "I feel that co-payments for medication are a great burden." & $2.32(1.17)$ & $231(44.08)$ \\
\hline "I frequently forget things on an everyday basis." & $1.90(1.01)$ & $147(28.05)$ \\
\hline "In general, I often feel bad, and sometimes I feel discouraged and depressed." & $2.00(1.07)$ & $162(30.92)$ \\
\hline $\begin{array}{l}\text { "I frequently have problems when taking my medication. Especially the use of my inhalers is causing } \\
\text { problems, and I am unsure whether I am using them in the right way." }\end{array}$ & $1.09(0.37)$ & $9(1.72)$ \\
\hline $\begin{array}{l}\text { "I have to overcome barriers to access my healthcare (e.g., my doctor/pharmacy is far away, I am depend- } \\
\text { ent on the help of others when I need to see my doctor)." }\end{array}$ & $1.55(0.98)$ & $98(18.70)$ \\
\hline $\begin{array}{l}\text { "I require help on an everyday basis (specifically with regards to my drug therapy and inhalers). However, } \\
\text { I do not receive any." }\end{array}$ & $1.10(0.40)$ & $12(2.29)$ \\
\hline "I am very afraid of the side effects of my medications." & $1.86(1.05)$ & $144(27.48)$ \\
\hline $\begin{array}{l}\text { "In case I already noticed or in case I would notice side effects related to my medication: I have discussed/ } \\
\text { would discuss them with my doctor as soon as possible." }\end{array}$ & $1.16(0.54)$ & $19(3.63)$ \\
\hline $\begin{array}{l}\text { "In case I already noticed or in case I would notice side effects related to my medication: I have stopped/ } \\
\text { would stop taking my medications or took/would take less of them." }\end{array}$ & $1.79(1.12)$ & $142(27.10)$ \\
\hline
\end{tabular}

ABQ-Asthma Adherence Barriers Questionnaire for Asthma, SD standard deviation

\section{Discussion}

\subsection{Key Results}

The main purpose of this analysis was to investigate adherence barriers in German patients with asthma by combining survey, clinical, and claims data. In total, we assessed 16 different adherence barriers via the ABQ-Asthma. Our results showed that most patients were affected by at least three adherence barriers (61.1\%), and only $6.1 \%$ were not affected by any of the assessed barriers.

The number and type of barriers reported by the patient had a considerable impact on treatment adherence. Treatment adherence decreased with an increasing number of patient-reported barriers. In addition, some of the patient-reported barriers had a generally higher impact on patients' adherence than other patient-reported barriers. We identified four barriers that showed significant influence on the NA probability. Of these, three barriers belonged to the group of intentional factors such as the patients' attitudes and beliefs (attitude regarding the fear of side effects, the perception that all medications are harmful, beliefs regarding own health). The fourth barrier was a treatment-related factor and referred to the fact that patients frequently having problems with the application of their medicine experienced a higher NA risk.

Furthermore, the analyzed patients could be classified into four different clusters regarding existing barriers. Two clusters were generally characterized by the number of existing barriers, where the cluster with a general low barrier 


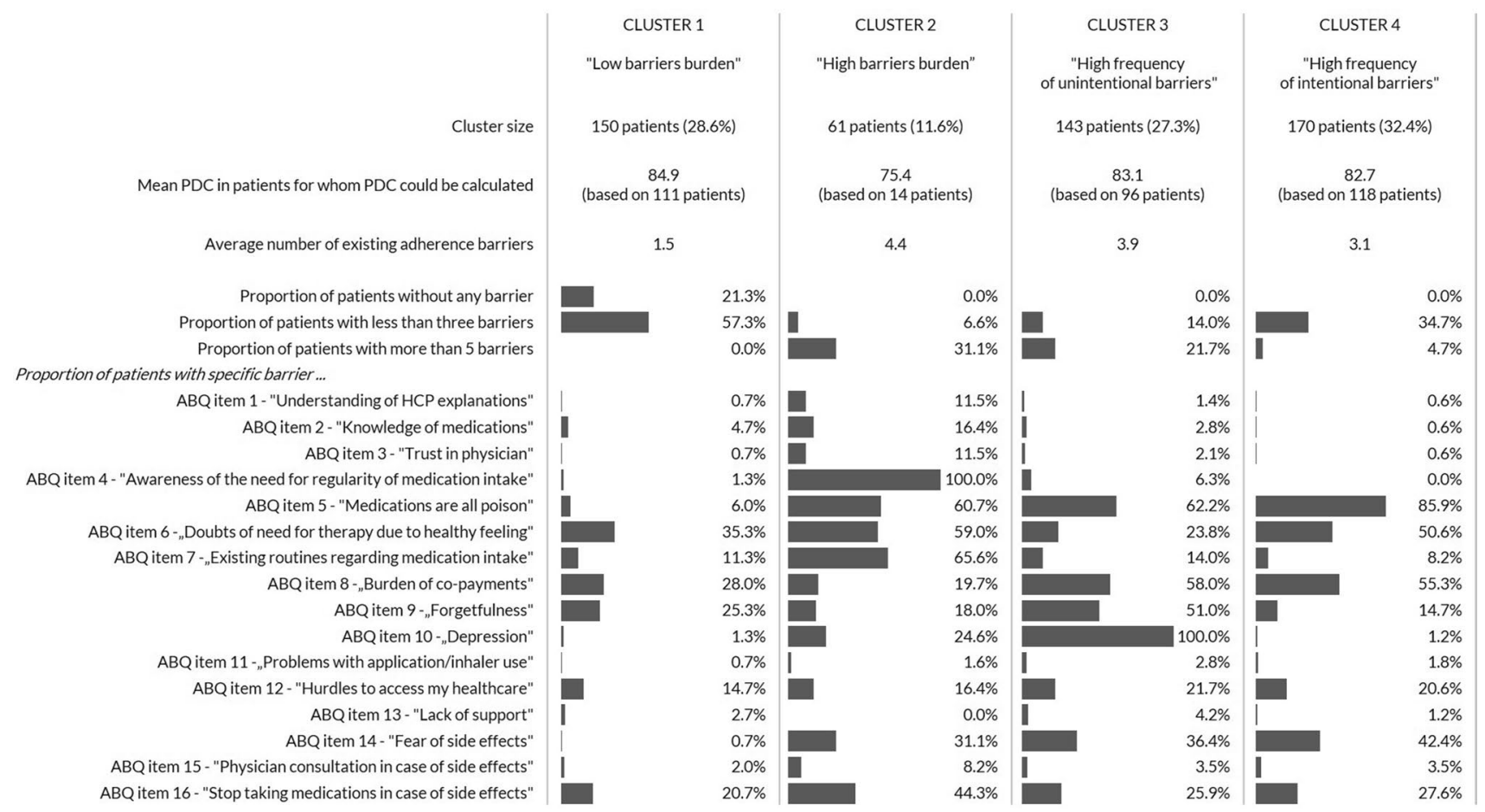

Fig. 1 Patient clusters identified based on different adherence barriers assessed with the Adherence Barriers Questionnaire for Asthma (ABQAsthma). $P D C$ proportion of days covered, $H C P$ health care provider

burden also showed the highest mean PDC. The two other clusters were more characterized by the type of present barriers, with one cluster being more driven by unintentional factors and the other by intentional barriers.

Previous studies investigated reasons explaining medication-related NA among patients with asthma. A systematic literature review identified in this respect, amongst others, patients' knowledge/education, inhaler device convenience and satisfaction, age, and adverse effects as common reasons for low adherence [21]. Another questionnaire-based analysis supported these findings and reported younger age to be a significant predictor of NA to inhalation regimens in patients with asthma [22]. Additionally, the presence of comorbidities was reported to be a predictor in this respect [23]. Another observational study found that the beliefs of patients play a major role with regard to their adherence. As an example, the study reported that patients with asthma who were convinced that their health depends on the asthma treatment were less likely to have poor treatment adherence and that if patients felt that without medication life would be impossible, the risk to have poor treatment adherence was rapidly reduced [24]. This was also shown by another observational analysis in Germany that reported that specific beliefs about the necessity of medicines were positively associated with medication adherence. In contrast, general beliefs about harm and overuse of medicines by doctors were negatively associated with medication adherence [25].
Our study confirmed that there is a considerable extent of adherence barriers in patients with asthma and that these barriers, with a variation across the different types of barriers highlighting the importance of patient-related intentional factors, are associated with the NA probability. All barriers assessed in our study, using the ABQ-Asthma, are potentially modifiable in a direction reducing the NA risk. Thus, early detection of these barriers can build the basis for individually tailored interventions promoting treatment adherence. We identified different patient clusters regarding the relevance of analyzed adherence barriers. Future adherence interventions might increase their effectiveness by segmenting patients, as the above different patient clusters require different approaches to improve their adherence.

\subsection{Limitations}

We acknowledge some limitations of our study. First, becaue of the study design, which aimed to link claims data from a regional German sickness fund with data from a prospective observational study, patients included in this analysis were based in the regions of Saxony and Thuringia. Thus, patients may not be representative of the whole of Germany. Second, even if the study sites were requested to include patients consecutively, there is a certain risk of selection bias because patients with more regular visits (and thus a better adherence behavior) were more likely to be overrepresented 
in the study. Furthermore, although we used a well-established instrument to assess adherence barriers and the research team, including clinical experts, tried to cover all available evidence on NA causes in patients with asthma, there is a certain risk that we did not cover all patient-related barriers. Further research is needed to investigate whether other relevant factors need to be considered. Additionally, we decided to assess the adherence based on claims data as a more objective measure than a self-reported measure. However, even if the means of assessing adherence was more objective, we faced issues that for a certain number of patients no evaluation could be done because the patient did not receive at least two prescriptions of a maintenance/ controller medication in the follow-up period. This might be an indicator that patients already discontinued the treatment but could also signal that we observed patients who do not need long-term medication. Furthermore, it needs to be mentioned that the PDC threshold of $80 \%$ used to define NA is not validated for asthma. Even if the 0.80 threshold has become a type of standard across indications, the optimal adherence threshold may vary by nature of disease, treatment, and outcomes. Finally, future research should assess existing barriers at the start of treatment and assess adherence as well as the development of the barriers over time.

\section{Conclusions}

We identified a high burden of adherence barriers in patients with asthma. Besides the impact of difficulties with the application of the medications, we highlighted the importance of intentional patient-related factors. Four different patient groups were identified that were inherently very homogeneous but heterogeneous to the other groups regarding existing adherence barriers and, thus, may need to be addressed separately in adherence programs. Our study results provide important starting points for future research and the further development of adherence programs, with specific consideration of patients' beliefs and perceptions and the fact that there exist different patient clusters regarding the relevance of different adherence barriers.

\section{Declarations}

Funding This study (HO-14-14930) is funded by GlaxoSmithKline.

Conflicts of Interest/Competing Interests Fraence Hardtstock and Sabrina Mueller are employees of Ingress-Health. Ingress-Health work was financially supported by GSK. Thomas Wilke is an employee of IPAM and received funding from GSK to conduct this study. Thomas Wilke has received honoraria from several pharmaceutical/ consultancy companies (Novo Nordisk, Abbvie, Merck, GSK, BMS, LEO Pharma, Astra Zeneca, Bayer, Boehringer Ingelheim, Pharmerit). Victoria Unmuessig and Robert Welte are GSK employees and hold stocks and shares. Ulf Maywald has no potential conflicts of interest, except those potentially related to his employer, AOK PLUS. Hartmut Timmermann has received consultancy fees and grants from several pharmaceutical companies.

Ethics Approval The study was approved by the Ethics Committee of the University Medicine Rostock (Germany) and the Saxon State Ministry for Social Affairs and Consumer Protection.

Consent to Participate Not applicable.

Consent for Publication Not applicable.

Availability of Data and Material The data that support the findings of this study are abstracted from individual patient records. Data were available for research purposes from the sickness fund upon request, in an anonymized form. Because of the German data protection law (SGB $\mathrm{X}$ ) and restrictions around revealing patients' confidential information, data are neither publicly available nor can be shared further.

Code Availability Not applicable.

Authors Contributions All authors have completed the author consent form and made substantial contributions to all of the following: (1) the conception and design of the study, or acquisition of data, or analysis and interpretation of data; (2) drafting the article or revising it critically for important intellectual content, and (3) final approval of the version to be submitted. Specifically, the main tasks the authors were engaged in were: FH, SM: study concept, statistical analysis, interpretation of results, writing all parts of the paper, review and revision; TW: study concept, project lead, participated in writing all parts of the paper; HT, VU, RW: study concept, interpretation of results, critical review of the manuscript; UM: data collection/validation, interpretation of results, critical review of the manuscript.

Open Access This article is licensed under a Creative Commons Attribution-NonCommercial 4.0 International License, which permits any non-commercial use, sharing, adaptation, distribution and reproduction in any medium or format, as long as you give appropriate credit to the original author(s) and the source, provide a link to the Creative Commons licence, and indicate if changes were made. The images or other third party material in this article are included in the article's Creative Commons licence, unless indicated otherwise in a credit line to the material. If material is not included in the article's Creative Commons licence and your intended use is not permitted by statutory regulation or exceeds the permitted use, you will need to obtain permission directly from the copyright holder. To view a copy of this licence, visit http://creativecommons.org/licenses/by-nc/4.0/.

\section{References}

1. World Health Organization. Asthma: key facts. 2017. https://www. who.int/news-room/fact-sheets/detail/asthma. Accessed 25 Jun 2019.

2. RKI. 12-month prevalence of asthma among adults in Germany. Berlin: Robert Koch Institute; 2017.

3. Global Initiative for Asthma. Global strategy for asthma management and prevention. http://www.ginasthma.org. Accessed $11 \mathrm{Feb}$ 2020.

4. Phan HT, Vu GV, Vu GT, Ha GH, Pham HQ, et al. Global mapping of research trends on interventions to improve health-related quality of life in asthma patients. Int J Environ Res Public Health. 2020;17(10):3540. 
5. Buhl R, Bals R, Baur X, Berdel D, Criée C-P, Gappa M, et al. S2kLeitlinie zur Diagnostik und Therapie von Patienten mit Asthma. Pneumologie. 2017;71:849-919.

6. Price D, Fletcher M van der MT. Asthma control and management in 8,000 European patients: the REcognise Asthma and LInk to Symptoms and Experience (REALISE) survey. NPJ Prim Care Respir Med. 2014;24:14009.

7. Arzneimittelkommission der Deutschen Apotheker, Arzneimittelkommission der deutschen Ärzteschaft, Deutscher Allergie- und Asthmabund, Deutsche Atemwegsliga, Deutsche Gesellschaft für Allergologie und klinArzneimittelkommission der Deutschen Apotheker, Arz DG für A und F et al. NVL Asthma-Langfassung, 3. Auflage Bundesärztekammer (B̈̈K); Kassenärztliche Bundesvereinigung (KBV); Arbeitsgemeinschaft der Wissenschaftlichen Medizinischen Fachgesellschaften. 20178.

8. Nieuwlaat R, Wilczynski N, Navarro T, Hobson N, Jeffery R, Keepanasseril A, et al. Interventions for enhancing medication adherence. Cochrane Database Syst Rev. 2014;(11):CD00011.

9. Osterberg L, Blaschke T. Adherence to medication. N Engl J Med. 2005;353(5):487-97.

10. Engelkes M, Janssens HM, de Jongste JC, Sturkenboom MC, Verhamme KM. Medication adherence and the risk of severe asthma exacerbations: a systematic review. Eur Respir J. 2015;45:396-407.

11. Lu Y, Mak KK, van Bever HP, Ng TP, Mak A, Chun-Man Ho R. Prevalence of anxiety and depressive symptoms in adolescents with asthma: a meta-analysis and meta-regression. Pediatr Allergy Immunol. 2012;23(8):707-15.

12. Janson SL, McGrath KW, Covington JK, Cheng SC, Boushey HA. Individualized asthma self-management improves medication adherence and markers of asthma control. J Allergy Clin Immunol. 2009;123:840-6.

13. Stoloff SW, Stempel DA, Meyer J, Stanford RH, Carranza Rosenzweig JR. Improved refill persistence with fluticasone propionate and salmeterol in a single inhaler compared with other controller therapies. J Allergy Clin Immunol. 2004;113:245-51.

14. Mosnaim GS, Pappalardo AA, Resnick SE, Codispoti CD, Bandi $\mathrm{S}$, Nackers L, et al. Behavioral interventions to improve asthma outcomes for adolescents: a systematic review. J Allergy Clin Immunol Pract. 2016;4:130-41.
15. Otsuki M, Eakin MN, Rand CS, Butz AM, van Hsu D, Zuckerman IH, et al. Adherence feedback to improve asthma outcomes among inner-city children: a randomized trial. Pediatrics. 2009; 124:1513-21.

16. Bender BG. Non-adherence to asthma treatment: getting unstuck. J Allergy Clin Immunol. 2016;4:849-51.

17. Nathan RA, Sorkness CA, Kosinski M, Schatz M, Li JT, Marcus P, et al. Development of the asthma control test: a survey for assessing asthma control. J Allergy Clin Immunol. 2004;113:59-65.

18. Mueller S, Wilke T, Gorasso V, Erhart M, Kittner JM. Adaption and validation of the adherence barriers questionnaire for HIV patients on antiretroviral therapy (ABQ-HIV). BMC Infect Dis. 2018;18:599.

19. Müller S, Kohlmann T, Wilke T. Validation of the Adherence Barriers Questionnaire: an instrument for identifying potential risk factors associated with medication-related non-adherence. BMC Health Serv Res. 2015;15:153.

20. Mueller S, Gorasso V, Hardtstock F, Wilke T. PRS59 adaption of the Adherence Barriers Questionnaire (ABQ) for use in patients with chronic obstructive pulmonary disese (COPD). Value Health. 2019;22:S882-3.

21. Mäkelä MJ, Backer V, Hedegaard M, Larsson K. Adherence to inhaled therapies, health outcomes and costs in patients with asthma and COPD. Respir Med. 2013;107:1481-90.

22. Takemura M, Nishio M, Fukumitsu K, Takeda N, Ichikawa H, Asano T, et al. Optimal cut-off value and clinical usefulness of the adherence starts with knowledge- 12 in patients with asthma taking inhaled corticosteroids. J Thorac Dis. 2017;9:2350-9.

23. Md Redzuan A, Lee MS Shah NM. Adherence to preventive medications in asthmatic children at a tertiary care teaching hospital in Malaysia. Patient Prefer Adherence. 2014;8:263-70.

24. Smits D, Brigis G, Pavare J, Maurina B, Barengo NC. Factors related to good asthma control using different medical adherence scales in Latvian asthma patients: an observational study. NPJ Prim Care Respir Med. 2017;27:39.

25. Brandstetter S, Finger T, Fischer W, Brandl M, Böhmer M, Pfeifer $\mathrm{M}$, et al. Differences in medication adherence are associated with beliefs about medicines in asthma and COPD. Clin Transl Allergy. 2017;7:39. 